\title{
Holocalyx balansae: ASPECTOS FENOLÓGICOS, MORFOLÓGICOS E GERMINAÇÃO DE SEMENTES
}

\author{
Marciele Felippi ${ }^{1}$, Solon Jonas Longhi ${ }^{2}$, Maristela Machado Araújo ${ }^{3}$ \\ ${ }^{1}$ Bióloga, Enga Florestal, Dr ${ }^{\mathrm{a}}$., UTFPR, Curitiba, PR, Brasil - marcielefelippi@utfpr.edu.br \\ ${ }^{2}$ Eng. Florestal, Dr., UFSM, Santa Maria, RS, Brasil - longhi.solon@gmail.com \\ ${ }^{3}$ Eng $^{\mathrm{a}}$ Florestal, Dr ${ }^{\mathrm{a}}$., UFSM, Santa Maria, RS, Brasil - araujo.maristela@gmail.com \\ Recebido para publicação: 04/03/2013 - Aceito para publicação: 31/03/2014
}

\begin{abstract}
Resumo
O reduzido conhecimento sobre aspectos básicos relacionados à autoecologia de espécies florestais nativas inviabiliza a elaboração de estratégias para o manejo adequado de florestas, restauração e produção de mudas. Assim, o estudo teve como objetivo caracterizar a época de floração e frutificação, morfologia da flor, fruto, semente, plântula e muda de Holocalyx balansae Micheli (alecrim), além de analisar características físicas e fisiológicas de um lote de sementes. As observações fenológicas foram realizadas mensalmente. O lote de sementes foi formado a partir de seis indivíduos que apresentaram frutos maduros no mesmo período. A presença de flores ocorreu em dois períodos (fevereiro e junho a setembro), da mesma forma que os frutos maduros (novembro e de março a abril). Observaram-se variações fenológicas, conforme o ano e entre árvores no mesmo período, sugerindo a marcação de maior número de exemplares arbóreos marcados do que se deseja coletar. A germinação é hipógea. O tamanho dos frutos e sementes foi variável, resultando em 793 sementes por quilograma, com $83 \%$ de germinação, entretanto, sob condições ambientais, ao observar a emergência das plântulas, esse valor decresceu expressivamente $(51 \%)$, devendo este ser um fator considerado no planejamento de produção de mudas.
\end{abstract}

Palavras-chave: Papilionoideae; floração; frutificação; emergência; muda.

\begin{abstract}
Holocalyx balansae: phenological and morphological aspects, and seed germination. The lack of knowledge about basic aspects related to autoecology of native forest species prevents the development of strategies for appropriate forest management, restoration and production of seedlings. This research aimed to characterize the time of flowering and fruitification, the morphology of flowers, fruits, seeds, seedling and changes of Holocalyx balansae Micheli (rosemary), and analyzing physical and physiological characteristics of a seed lot. We conducted monthly phenological observations. The seed lot had six individuals that exhibited ripe fruits in the same period. The presence of flowers occurred in two periods (February and June to September), just as the ripe fruit (November and March to April). We observed phenological changes during the year between trees in the same period, suggesting that it is necessary to mark a largest number of arboreal specimens than the ones you want to collect. Germination is hypogeal. The size of the fruits and seeds was variable, resulting in 793 seeds per kilogram, with $83 \%$ of germination, however, under environment conditions, observing seedling emergence, this value decreased significantly (51\%), it should be a factor to be considered in seedling production planning.
\end{abstract}

Keywords: Papilionoideae; flowering; fruiting; emergency; seedling.

\section{INTRODUÇÃO}

Os recursos florestais nativos têm sido degradados, em função da exploração madeireira e abertura de frentes agrícolas. Consequentemente, populações de diversas espécies, como das arbóreas, vêm sofrendo forte pressão, mesmo antes de se ter domínio de como reproduzi-las. Outro fato que vem ocorrendo é o aumento de áreas alteradas e da demanda por sementes de espécies florestais nativas com qualidade (SILVA; HIGA, 2006). 
Os projetos de restauração necessitam de elevado número de espécies regionais, o que depende dos conhecimentos fenológicos, morfológicos, germinativos e silviculturais, constituindo o ponto de partida para a produção de mudas de qualidade.

A fenologia analisa a época de reprodução da espécie e o comportamento de polinizadores durante a floração (NEWSTROM et al., 1994). A morfologia de órgãos reprodutivos e vegetativos possui papel fundamental na compreensão do ciclo de vida, dos processos germinativos e do desenvolvimento das plantas. Apesar dos inúmeros estudos em relação às espécies florestais, ainda se fazem necessárias pesquisas que permitam caracterizar as fases de desenvolvimento da flor e do fruto, até que haja a formação da muda, subsidiando informações à tecnologia de sementes e aos viveiros.

O gênero Holocalyx Micheli, constituído por apenas uma espécie, $H$. balansae Micheli (MANSANO; VIANNA FILHO, 2004), pertence à família Fabaceae e à subfamília Papilionoideae (LEWIS et al., 2005). Esta compreende 28 tribos e cerca de 13.800 espécies (POLHILL, 1981; LEWIS et al., 2005).

Na literatura, H. balansae, conhecida como alecrim, pau-alecrim, alecrim-do-campo (LORENZI, 2002; CARVALHO, 2003) é descrita como árvore frondosa de caule tortuoso, de altura de 15 a $25 \mathrm{~m}$ e tronco com 50 a $80 \mathrm{~cm}$ de diâmetro, com casca cinzenta escura, fina e quase lisa. Essa espécie é semidecídua, com folhas alternas, paripinadas com numerosos folíolos oblongos, estreitos e com venação densa, enquanto as flores são pequenas, com dez estames livres. O alecrim ocorre em solos rochosos e úmidos de boa fertilidade, estando ausente em solos encharcados. Apesar de sua ocorrência no interior da mata primária, tolera bem a luz direta quando adulto (BURKART, 1979; LORENZI, 2002).

A espécie é uma árvore característica da Floresta Estacional Decidual do Alto Uruguai (MARCHIORI, 1997), sendo amplamente utilizada em marcenaria, reflorestamento ambiental (CARVALHO, 2003) e arborização urbana (SOUZA; LORENZI, 2008).

Conforme Battilani et al. (2006), o alecrim apresenta frutos com atrativos para vertebrados frugívoros, tornando a espécie importante para a fauna local. Lorenzi (2002) descreveu que a germinação das sementes do alecrim ocorre entre 30 e 60 dias após a semeadura, enquanto Carvalho (2003) verificou até 120 dias, com 50 a $90 \%$ das sementes germinadas.

Contudo, apesar de $H$. balansae estar contemplada na literatura quanto aos aspectos relacionados à distribuição geográfica, descrição botânica, germinação de sementes e uso, ainda muitas informações são necessárias para viabilizar sua utilização comercial ou ambiental. Como lacuna de informação, destacam-se a época adequada para a coleta de sementes, diretrizes para definição do número de árvoresmatrizes para coleta, caracterização morfológica das sementes, viabilizando análise por meio de testes de tetrazólio e raios X, e definição da quantidade de sementes necessárias para compor determinado lote.

Assim, o presente estudo teve como objetivos identificar o período de floração e frutificação, descrever e ilustrar a morfologia da flor, do fruto, da semente, da plântula e da muda, além de quantificar o número de sementes por quilograma, associado ao teor de água, germinação e emergência de sementes de alecrim.

\section{MATERIAL E MÉTODOS}

O trabalho foi realizado de março de 2007 a março de 2010. A coleta do material botânico e as observações fenológicas ocorreram no município de Frederico Westphalen, RS, sendo as descrições morfológicas e a análise de sementes, realizadas no Laboratório de Silvicultura da Universidade Federal de Santa Maria (UFSM), RS.

A região de coleta situa-se a $566 \mathrm{~m}$ de altitude, com classificação climática, segundo Köppen, do tipo Cfa, precipitação pluvial com média anual entre 1.800 e $2.100 \mathrm{~mm}$ e temperatura média anual em torno de $18^{\circ} \mathrm{C}$ (RIO GRANDE DO SUL, 2001).

Durante o período de estudo, foram obtidos dados climáticos junto à Estação Meteorológica do Centro de Educação Superior Norte do Estado do Rio Grande do Sul (CESNORS). Entretanto, os dados pluviométricos somente foram coletados a partir de 2008 (Figura 1).

Foram observadas 20 árvores-matrizes, adultas, com copa bem distribuída e fuste reto, distantes pelo menos $100 \mathrm{~m}$ entre si (PIÑA-RODRIGUES et al., 2007).

As árvores-matrizes foram monitoradas mensalmente, com binóculo, para observação de cada fenofase, seguindo o método qualitativo utilizado por Fournier (1974), sendo a floração caracterizada, conforme Morellato et al. (1989), como o período em que as árvores apresentam flores em antese, e a frutificação, quando os frutos encontram-se maduros. 


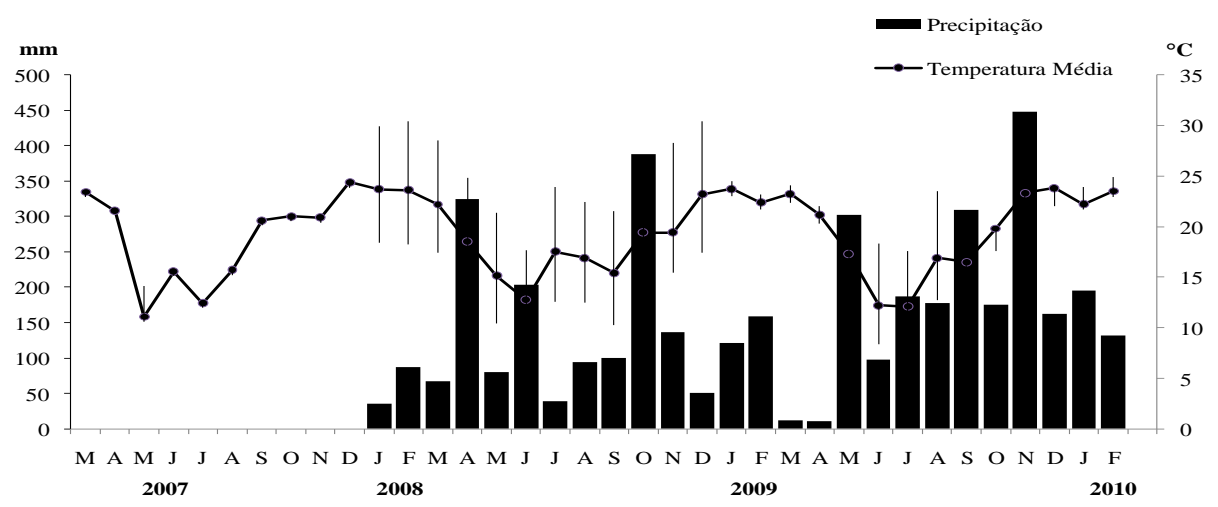

Figura 1. Precipitação $(\mathrm{mm})$ e temperatura $\left({ }^{\circ} \mathrm{C}\right)$, média mensal no município de Frederico Westphalen, RS, no período de observações fenológicas (março de 2007 a março de 2010). Fonte: Estação Climatológica do Centro de Educação Superior Norte do Rio Grande do Sul (CESNORS) UFSM. Linhas verticais: temperatura máxima e mínima mensal.

Figure 1. Precipitation $(\mathrm{mm})$ and temperature $\left({ }^{\circ} \mathrm{C}\right)$, monthly average in the City of Frederico Westphalen, RS, during the period of phenological observations (March 2007 to March 2010). Source: Climatological Station of the Center for Higher Education North of Rio Grande do Sul (CESNORS) - UFSM. Vertical lines: monthly minimum and maximum temperature.

Após o início dos eventos fenológicos, as observações passaram a ser quinzenais, a fim de serem analisados os padrões de frequência de indivíduos e ocorrência de cada fenofase, conforme indicado por Newstrom et al. (1994), associando essas informações às condições climáticas.

Da copa de cada árvore-matriz foram coletadas, aleatoriamente, 50 flores e 10 frutos maduros, amarelos, inteiros e aparentemente sadios. O material botânico foi preservado em álcool (70\%), para posterior análise, descrição e ilustração morfológica em laboratório.

Durante a fase de maturação, foi realizada a coleta de frutos em seis indivíduos com maturação sincrônica. Em seguida, os frutos foram despolpados em água corrente, para a separação do lote de sementes.

A caracterização morfológica foi realizada por meio de análise externa e interna de flores, frutos e sementes, e externa das plântulas e mudas. Foram utilizados lupa de mesa do tipo SZ40 Olympus e paquímetro mecânico $(1 / 50 \mathrm{~mm})$.

$\mathrm{Na}$ descrição das flores, analisou-se o tipo de inflorescência, o número e disposição de cada um dos verticilos florais, a posição do ovário, o tipo de estigma, o sexo e o número, coloração e textura de pétalas e sépalas. Nos frutos, observou-se a textura, a consistência, a pilosidade, a forma e o número de sementes por fruto. Já nas sementes, observaram-se a cor, a consistência, a forma, a superfície, o tamanho, a micrópila, a rafe e o hilo. No embrião foi observada sua posição, forma e tamanho, assim como textura e forma dos cotilédones.

Tanto para frutos quanto para sementes, utilizando-se 200 exemplares de cada, foram registrados os valores correspondentes a mínima, máxima e média referente ao comprimento, à largura e à espessura.

Para monitoramento e ilustrações do desenvolvimento da plântula, as sementes foram colocadas para germinar em substrato papel germitest, em germinador do tipo Mangelsdorf, sob temperatura de $25^{\circ} \mathrm{C}$, na presença de luz branca, sendo utilizadas duas repetições de 20 sementes cada. Foi realizada semeadura direta em 50 sacos de polietileno, para análise, descrição e ilustração dos indivíduos que atingiram $3 \mathrm{~mm}$ de diâmetro do colo e $20 \mathrm{~cm}$ de altura, considerados muda conforme Gonçalves e Benedetti (2001). Foram descritos e ilustrados raiz, colo, hipocótilo, epicótilo, cotilédones, eófilo e metáfilo.

A metodologia e a terminologia empregadas para descrição morfológica basearam-se em Vidal e Vidal (2000), Souza (2003) e Gonçalves e Lorenzi (2007).

A partir da coleta e formação do lote, foram retiradas 8 amostras de 100 sementes para determinar o peso de mil sementes, e duas amostras de $8 \mathrm{~g}$ para teor de água, conforme Regras para 
Análise de Sementes (BRASIL, 2009).

O teste de germinação foi conduzido com oito repetições de 25 sementes, em gerbox, contendo vermiculita média esterilizada em autoclave durante o período de $1 \mathrm{~h}$ a $120^{\circ} \mathrm{C}$. Na montagem do teste, a vermiculita foi umedecida a $60 \%$ de capacidade de retenção de água. As amostras foram postas em germinador regulado a $25{ }^{\circ} \mathrm{C} \pm 3{ }^{\circ} \mathrm{C}$, com luz branca contínua, considerando-se germinadas após a emissão da raiz primária (GUI-FERREIRA; BORGHETTI, 2004).

$\mathrm{O}$ teste de emergência foi realizado em casa de vegetação, utilizando-se 54 tubetes em quatro repetições, totalizando 216 mudas. Tubetes de $175 \mathrm{~cm}^{3}$ foram preenchidos com substrato MecPlant Florestal $3^{\circledR}$, irrigados duas vezes ao dia e avaliados diariamente. As sementes foram consideradas emergidas a partir do aparecimento dos primórdios foliares, conforme descrito por Gui-Ferreira e Borghetti (2004).

Para os dados de laboratório e viveiro, foram analisados a porcentagem de germinação e de emergência (BORGHETTI; GUI-FERREIRA, 2004) e o índice de velocidade de germinação e de emergência, conforme Maguire (1962).

\section{RESULTADOS E DISCUSSÃO}

O florescimento ocorreu de junho a setembro, com pico nos meses de agosto e setembro (Figura 2), sendo que alguns indivíduos floresceram no mês de fevereiro. Lorenzi (2002) também citou a presença de plantas com flores duas vezes ao ano. Pressupõe-se, a partir de tais informações, que a espécie seja bianual, no entanto são necessários estudos criteriosos, observando-se um número maior de indivíduos, a fim de confirmar tal característica.

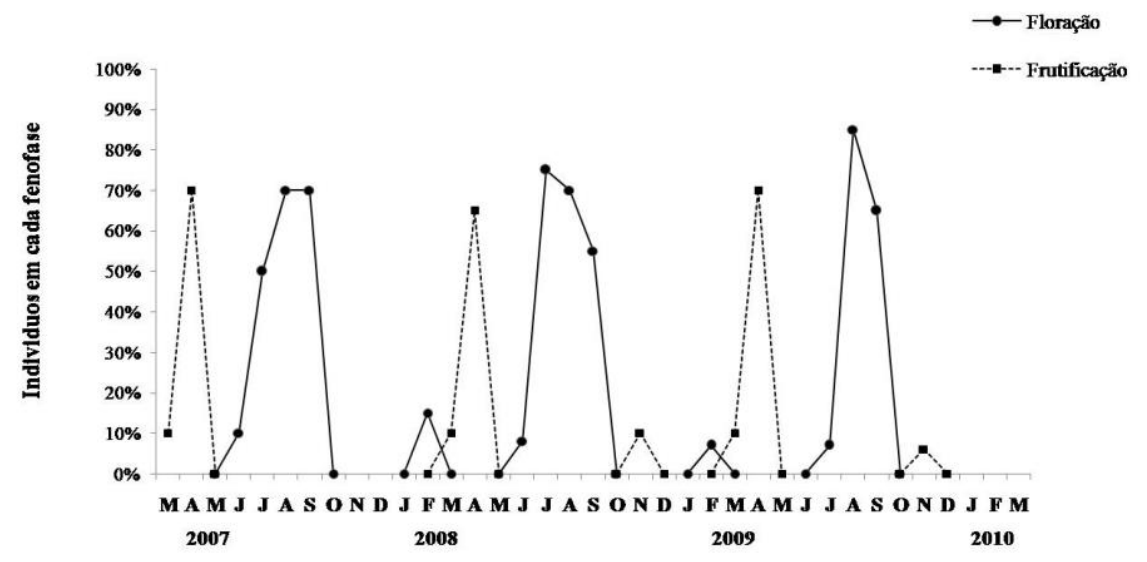

Figura 2. Padrão da sazonalidade da floração e frutificação de Holocalyx balansae durante o período de março de 2007 a janeiro de 2010 no município de Frederico Westphalen, RS.

Figure 2. Pattern of seasonality of flowering and fruiting of Holocalyx balansae from March 2007 to January 2010, in the City of Frederico Westphalen, RS.

De acordo com Reis e Kageyama (2008), a partir do momento em que exista oferta de flores durante todo o ano, a chance dos diferentes grupos de polinizadores se estabelecerem na área fica maior, aumentando, assim, a teia de relações no ecossistema. A presença de flores foi perceptível durante a transição do período seco para o de umidade na região. Observou-se, durante o ano de 2009, maior número de indivíduos florescendo, ocasião na qual o índice pluviométrico foi elevado (Figura 1), quando comparado aos anos de 2007 e 2008, durante o mesmo período.

A floração na transição da estação seca para úmida ou no início da estação úmida, nas florestas semideciduais, tem sido atribuída, principalmente, à redução do estresse hídrico causado pelas primeiras chuvas após o período de seca, ao aumento do fotoperíodo e à elevação da temperatura (MORELLATO $e t$ al., 1989; MORELLATO, 1995).

O período de presença de flores para a região de estudo (junho a setembro) antecede a época 
citada por Carvalho (2003) para o Rio Grande do Sul (setembro a outubro). Lorenzi (2002) destacou ocorrência predominante de flores de outubro a novembro. Portanto, a atividade e a intensidade da fenofase de alecrim, neste trabalho, expressam dados diferentes dos relatados e complementares para o entendimento quanto ao comportamento da espécie em campo.

Já os frutos maduros foram observados em novembro e de março a abril. A falta de sincronismo na fase de frutificação, apesar de proporcionar recurso para a fauna por mais tempo e, possivelmente, maior possibilidade de regeneração natural para a espécie, dificulta a obtenção de um lote de sementes homogêneo em relação à maturação da semente. Consequentemente, há a necessidade de selecionar maior número de indivíduos para coleta de sementes (superior a 20), a fim de permitir número de árvoresmatrizes com frutos em quantidades e nível de maturação semelhante no mesmo período.

Analisando-se os aspectos morfológicos, observaram-se pequenas flores (Figura 3A) de coloração esbranquiçado-esverdeada, pilosas, com prefloração imbricada, constituindo inflorescência do tipo panícula. O cálice é piloso, gamossépalo e actinomorfo (Figura 3A), de coloração verde-clara. A corola é gamopétala, actinomorfa, tubulosa e caduca (Figura 3B). A flor é pedunculada, hermafrodita e hipógina (Figura 3A; B). O androceu é homodínamo e dialistêmone. Os estames, em número de 12, possuem filetes simples, inseridos na base das sépalas com anteras simples, basifixa (Figura 3B; C), com abertura longitudinal (rimosas), introrsas. O gineceu é unicarpelar, unilocular, com placentação parietal com 1 a 4 óvulos (Figura 3D; E) e estilete terminal com estigma indiviso (Figura 3B). Na base do ovário emergem pelos (Figura 3B; D) de coloração branca.
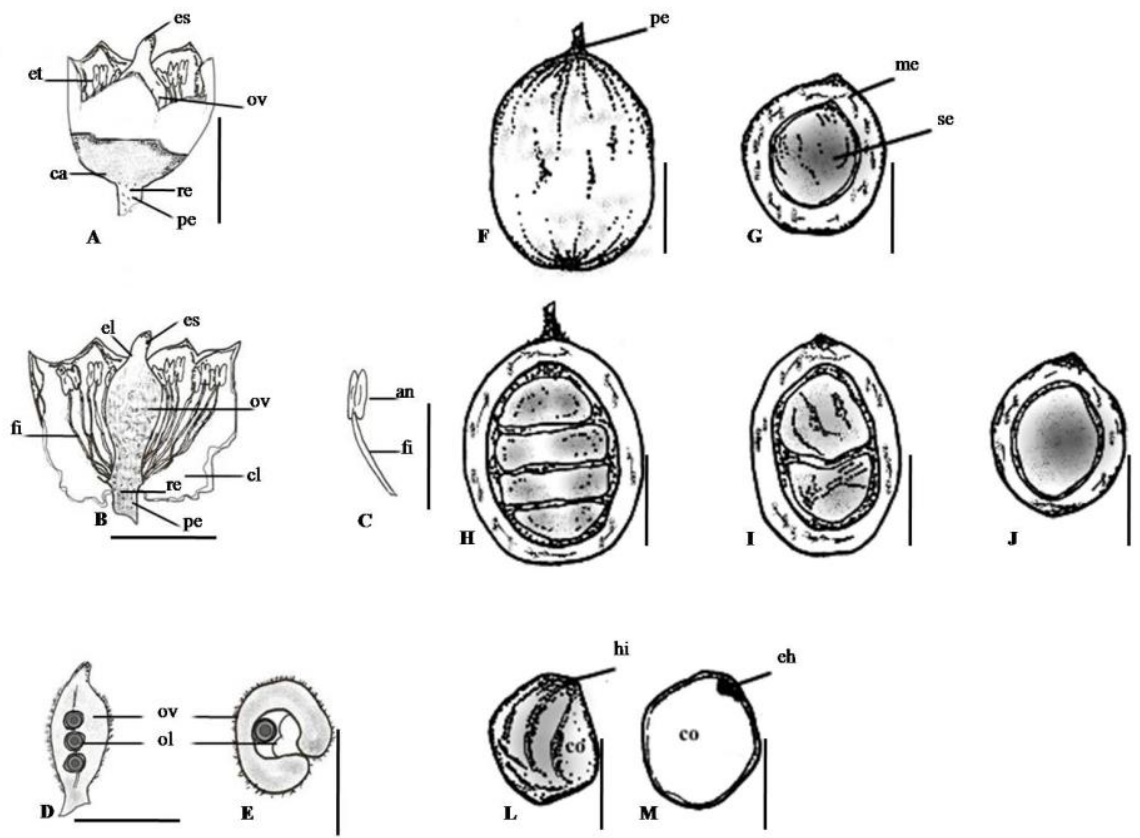

Figura 3. Flor, fruto e semente de Holocalyx balansae. A) Vista lateral da flor; B) Flor em corte longitudinal; C) Estame; D) Ovário em corte longitudinal; E) Ovário em corte transversal (an: antera; ca: cálice; cl: corola; eh: eixo hipocótilo-radícula; et: estame; el: estilete; es: estigma; fi: filete; hi: hilo; me: mesocarpo; ol: óvulo; ov: ovário; pe: pedúnculo; re: receptáculo; se: semente). Barra de escala $0,4 \mathrm{~cm}$ para $\mathrm{A}, \mathrm{B}, \mathrm{D}$ e E, $0,2 \mathrm{~cm}$ para $\mathrm{C}$ e $2 \mathrm{~cm}$ para as demais.

Figure 3. Flower, fruit and seed of Holocalyx balansae. A) Side view of flower; B) Flower in longitudinal section; C) Stamen; D) Ovary longitudinal section; E) Ovary in transverse section (an: anther; ca: calyx; cl: corolla; eh: hypocotyl-radicle axis; et: stamen; el: style; es: stigma; fi: filament; hi: hilo; me: mesocarp; ol: ovule; ov: ovary; pe: peduncle; re: receptacle; se: seed). Scale bar $0.4 \mathrm{~cm}$ for A, B, D and E, $0.2 \mathrm{~cm}$ to $\mathrm{C}$ and $2 \mathrm{~cm}$ for others. 
O fruto simples é uma baga, de formato globoso, indeiscente, superfície lisa (Figura 3F), de coloração amarela, mesocarpo (Figura 3G) carnoso, com dimensões variando de 1,9 a $3,2 \mathrm{~cm}$ de comprimento, 1,8 a $3 \mathrm{~cm}$ de largura e 1,5 a 2,8 cm de espessura (Tabela 1), contendo 1 a 4 sementes (Figura $3 \mathrm{H}$ a J), que são caracterizadas por superfície lisa (Figura 3L), formato variável, podendo ser oblongas a achatadas, com dimensões de 1,2 a 2,3 cm de comprimento, 1 a 1,6 cm de largura e 0,7 a $1,5 \mathrm{~cm}$ de espessura (Tabela 1). Essas sementes apresentam tegumento bastante fino, de coloração castanho-clara, com micrópila e rafe pouco evidentes, localizadas próximas ao hilo, que se encontra na região basal da semente (Figura $3 \mathrm{~L}$ ).

Internamente, a semente é exabulminosa, com embrião axial, cotilédones carnosos, grandes, com eixo hipocótilo-radícula curto e espesso (Figura 3M). Assim, considerando o tamanho e suas características internas, facilmente perceptíveis, as sementes podem ser analisadas com mais facilidade por meio de testes como o de tetrazólio e raios $\mathrm{X}$.

Tabela 1. Valores médios de comprimento, largura e espessura de frutos e sementes, coletados de seis matrizes de Holocalyx balansae, setembro de 2008, Frederico Westphalen, RS.

Table 1. Average values of length, width and thickness of fruits and seeds collected from six arrays of Holocalyx balansae, September 2008, Frederico Westphalen, RS.

\begin{tabular}{lcccccc}
\hline & & $\begin{array}{c}\text { Mínima } \\
(\mathbf{c m})\end{array}$ & $\begin{array}{c}\text { Máxima } \\
(\mathbf{c m})\end{array}$ & $\begin{array}{c}\text { Média } \\
(\mathbf{c m})\end{array}$ & $\begin{array}{c}\text { Desvio } \\
\text { padrão }\end{array}$ & $\begin{array}{c}\text { CV } \\
(\mathbf{\%})\end{array}$ \\
\hline \multirow{3}{*}{ Frutos } & Comprimento & 1,9 & 3,2 & 2,6 & 0,4 & 15 \\
& Largura & 1,8 & 3 & 2,3 & 0,5 & 21 \\
\multirow{3}{*}{ Sementes } & Espessura & 1,5 & 2,8 & 2,2 & 0,4 & 18 \\
& Comprimento & 1,2 & 2,3 & 1,8 & 0,4 & 22 \\
& Largura & 1 & 1,6 & 1,3 & 0,2 & 17 \\
& Espessura & 0,7 & 1,5 & 1,1 & 0,3 & 23 \\
\hline
\end{tabular}

Ledo et al. (2002) relataram que o tamanho da semente é uma característica importante em estudos de uma espécie, podendo indicar a quantidade de reservas, o que, de acordo com Carvalho e Nakagawa (2012), pode estar associada ao vigor das plântulas.

Observaram-se 793 sementes de $H$. balansae por quilograma, com coeficiente de variação de $3,08 \%$ e teor de água de $45,5 \%$. O número de sementes por quilograma foi maior quando comparado a outros trabalhos, como de Pásztor (1963), Eibl et al. (1994) e Lorenzi (2002), os quais não apresentaram resultado referente ao teor de água. Essa diferença pode estar associada aos procedimentos adotados pelos autores para as análises. É importante ressaltar que, segundo Eibl et al. (1994), a semente do alecrim é recalcitrante, perdendo rapidamente a viabilidade quando armazenada em ambiente não controlado. $\mathrm{O}$ tamanho da semente é mantido por certo tempo. Após determinado período, dependendo da espécie, ocorre redução mais ou menos acentuada, o que corresponde ao período de rápida e intensa desidratação (CARVALHO; NAKAGAWA, 2012).

Considerando-se, neste trabalho, que as análises foram realizadas logo após a coleta, pressupõese que características genéticas e vigor das plantas progenitoras, assim como as condições climáticas predominantes durante a maturação da semente, como também o estádio de desenvolvimento do embrião podem ter influenciado tanto no tamanho quanto no teor de água das sementes.

A germinação foi de $83 \%$, iniciando a partir do $32^{\circ}$ dia, e a emergência $51 \%$, tendo início 40 dias após a semeadura. O índice de velocidade de germinação foi de 0,57 e o de emergência, 0,61. A baixa porcentagem de emergência indica que, para a produção de determinado lote de mudas de alecrim, é necessário obter maior quantidade de sementes, semeando-se mais de uma semente por recipiente ou, também, considerando o longo tempo para a emergência, usar sementeira, com posterior repicagem das plântulas para o recipiente.

A porcentagem de sementes germinadas de alecrim pode ser considerada elevada sob condições controladas, no entanto a avaliação da germinação por meio da emissão da raiz primária pode não representar boa alternativa no contexto silvicultural.

Observam-se, ainda, diferenças de porcentagem, comparando-se as informações registradas a partir deste estudo às de outros trabalhos, como Oliveira (2001), que aponta 74\% de emergência em casa de sombra, a partir dos 14 dias. Essa possível diferença pode estar associada a diferenças na qualidade 
genética e fisiológica das sementes, ou, ainda, a fatores ambientais durante a germinação, como por exemplo temperatura e umidade.

A germinação de alecrim é hipógea (Figura 4C; D), cujo processo de emergência iniciou-se, lentamente, pela protrusão da raiz primária entre o $32^{\circ}$ e $34^{\circ}$ dia após a semeadura (Figura 4A).

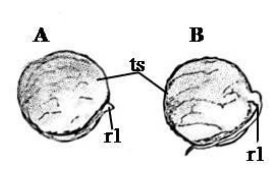

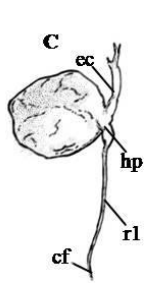

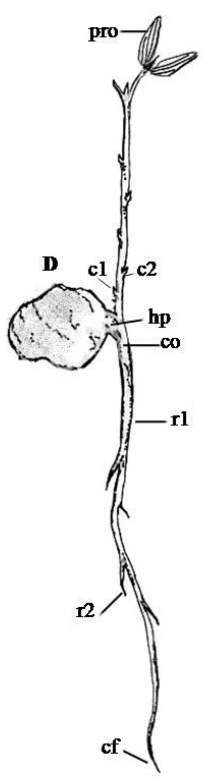

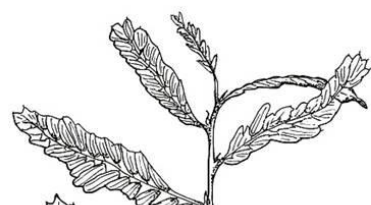
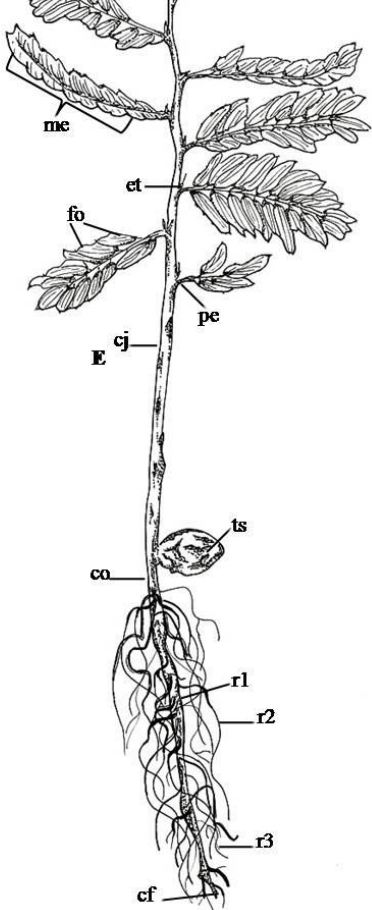

Figura 4. Estágios sucessivos de desenvolvimento inicial de Holocalyx balansae. A) Emissão da raiz primária ( $32^{\circ}$ ao $34^{\circ}$ dia); B) Alongamento da raiz primária; C) Emissão do epicótilo ( $47^{\circ}$ dia); D) Plântula $\left(60^{\circ}\right.$ dia); E) Muda $\left(120^{\circ}\right.$ dia). (c1, c2: catáfilos; cf: coifa; cj: caule jovem; co: colo; ec: epicótilo; et: estípula; me: metáfilo; fo: folíolo; hp: eixo hipocótilo-radícula; pro: protófilo; pe: pecíolo; r1: raiz primária; r2: raiz secundária; r3: raiz terciária; ts: tegumento seminal). Barra de escala: $2 \mathrm{~cm}$.

Figure 4. Successive stages of early development of Holocalyx balansae. A) Primary root emission (32 to $34^{\circ}$ day); B) Elongation of the primary root; C) Epicotyl emission (47th day); D) Young

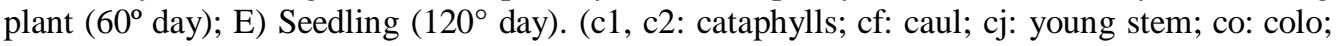
ec: epicotyl; et: stipule; me: metaphyll; fo: leaflet; hp: hypocotyl-radicle axis; pro: foliage leaf; pe: petiole; r1: primary root; r2: secondary root; $r 3$ : tertiary root; ts: seminal integument). Scale bar: $2 \mathrm{~cm}$.

Próximo ao $42^{\circ}$ dia, evidenciou-se o hipocótilo curto (Figura 4B). A emissão do epicótilo ocorreu por volta dos 47 dias, exibindo o primeiro catáfilo alterno (Figura 4C). Posteriormente, a produção de mais catáfilos alternos, seguida pela diferenciação do protófilo, aos 60 dias (Figura 4D). O protófilo é alterno, pinado, bifoliolado, curto-peciolado (Figura 4D) e com um par de estípulas filiformes curtas em sua base. O sistema radicular da plântula é simples, constituído pela raiz pivotante e poucas raízes secundárias de pequeno tamanho (Figura 4D). Sequencialmente são formadas mais folhas (metáfilos), nas quais são acrescentadas de dois a três pares de folíolos também subopostos (Figura 4E), 
estando a muda formada quatro meses após a semeadura, com aproximadamente $20 \mathrm{~cm}$ de comprimento e 4 mm de diâmetro do colo.

$\mathrm{Na}$ planta jovem, as folhas são compostas, folíolos opostos, paripenados, cuja base foliar é subcordada, com ápice foliar cuspidado e borda lisa levemente dentada de formato linear (Figura 4E), sendo a venação do tipo paralelódroma.

A descrição morfológica tratada neste trabalho confirmou algumas características da espécie e evidenciou aspectos morfológicos das plântulas e mudas, ainda não descritos e importantes para a análise de germinação em laboratórios de análise de sementes, a qualidade de mudas no viveiro e o reconhecimento da espécie a campo.

Esse estudo também mostrou restrições ao avanço silvicultural da espécie, imposto pela assincronia de produção de sementes e baixa e lenta emergência. Além disso, com base nos resultados do peso de 1000 sementes e emergência na região, para produção de 1000 mudas seria necessário adquirir cerca de $5 \mathrm{~kg}$ de sementes, considerando a utilização de duas sementes por recipiente.

Tendo em vista que a formação de um lote de qualidade necessita de elevado número de matrizes (superior a 20), seriam necessários grandes esforços e, consequentemente, custo de coleta, onerando a produção de mudas, podendo esse ser um fator limitante no uso dessa espécie em projetos de reflorestamento.

\section{CONCLUSÕES}

- A floração e frutificação de alguns indivíduos de $H$. balansae ocorrem em mais de uma ocasião do ano, obtendo-se o fruto maduro cerca de nove meses após a floração, nos meses de novembro e março a abril. Em função da assincronia na frutificação de alecrim, recomenda-se a seleção e marcação de um maior número de árvores (superior a 20), a fim de permitir maior quantidade de sementes em nível de maturação semelhante.

- A germinação de sementes de alecrim ultrapassa $80 \%$, enquanto a emergência, sob as condições testadas, ficou próxima de 50\%.

- A germinação de alecrim é hipógea, estando a muda formada, aproximadamente, quatro meses após emissão da radícula.

\section{REFERÊNCIAS}

BATTILANI, J. L.; SOUZA, A. L. T. S.; PEREIRA, S. R.; KALIFE, C.; SOUZA, P. R.; JELLER, H. Produção de sementes de espécies florestais nativas - Manual. Campo Grande, MS: Editora UFMS, 2006. $41 \mathrm{p}$.

BORGHETTI, F.; GUI-FERREIRA, A. Interpretação de resultados de germinação. In: GUI-FERREIRA, A.; BORGHETTI, F. (Orgs.). Germinação: do básico ao aplicado. Porto Alegre: Artmed, 2004. p. 209 222.

BRASIL. Ministério da Agricultura, Pecuária e Abastecimento. Secretaria de Defesa Agropecuária. Regras para análises de sementes. Brasília: Mapa/ACS, 2009. 399 p.

BURKART, A. Leguminosas Mimosoideas. In: REITZ, B.; KLEIN, R. M. (Orgs.). Flora Ilustrada Catarinense. Itajaí: Herbário Barbosa Rodrigues, 1979. 299 p.

CARVALHO, P. E. R. Espécies arbóreas brasileiras. Brasília: Embrapa Informações Tecnológicas; Colombo: Embrapa Florestas, 2003. v. 1. 1039 p.

CARVALHO, N. M.; NAKAGAWA, J. Sementes: ciência, tecnologia e produção. 5. ed. Jaboticabal: FUNEP, 2012. $590 \mathrm{p}$.

EIBL, B. I.; SILVA, F.; CARVALHO, A.; CZEREPAK, R.; KEHL, J. Ensayos de germinación y análisis cuantitativo en semillas de especies forestales nativas de Misiones, R. A. Yvyraretá, Eldorado, v. 5, n. 5, p. $33-48,1994$. 
FOURNIER, L. A. Un método cuantitativo para la medición de características fenológicas en árboles. Turrialba, San José, v. 24, n. 4, p. 422 - 423, 1974.

GONÇALVES, E. G.; LORENZI, H. Morfologia vegetal: organografia e dicionário ilustrado de morfologia das plantas vasculares. São Paulo: Instituto Plantarum de Estudos da Flora, 2007. 416 p.

GONÇALVES, J. L. M.; BENEDETTI, V. Nutrição e fertilização florestal. Piracicaba: IPEF, 2001. 427 p.

GUI-FERREIRA, A.; BORGHETTI, F. Germinação: do básico ao aplicado. Porto Alegre: Artmed, 2004. $323 \mathrm{p}$.

LEDO, A. S.; MEDEIROS-FILHO, S.; LEDO, F. J. S.; ARAÚJO, E. C. Efeito do tamanho de semente, do substrato e pré-tratamento em sementes de pupunha. Ciência Agronômica, Fortaleza, v. 33, n. 1, p. 29 $-32,2002$.

LEWIS, G. P.; SCHRIRE, B.; MACKINDER, B.; LOCK, M. Legumes of the World. The Royal Botanic Garden, Kew, 2005. 577 p.

LORENZI, H. Árvores brasileiras: manual de identificação e cultivo de plantas arbóreas nativas do Brasil. 4. ed., v.1, Nova Odessa: Plantarum, 2002. 368 p.

MAGUIRE, J. D. Speed of germination-aid in selection and evaluation for seedling emergence and vigor. Crop Science, v. 2, n. 1, p. 176 - 177, 1962.

MANSANO, V. de F.; VIANNA FILHO, M. D. M. Uma reavaliação taxonômica da América do Sul: gênero Holocalyx (Leguminosae, Papilionoideae). Brittonia, v. 62, n. 2, p. 110 - 115, 2004.

MARCHIORI, J. N. C. Dendrologia das angiospermas: leguminosas. Santa Maria: UFSM, 1997. 200 p.

MORELlATO, L. P. C. As estações do ano na floresta. In: MORELLATO, L. P. C.; LEITÃO FILHO, H. F. Ecologia e preservação de uma floresta tropical urbana: Reserva de Santa Genebra. Campinas: Editora da Unicamp, 1995. p. 37 - 41.

MORELLATO, L. P. C.; RODRIGUES, R. R.; LEITÃO-FILHO, H. F.; JOLY, C. A. Estudo fenológico comparativo de espécies arbóreas de floresta de altitude e floresta mesófila semidecídua na serra do Japi, Jundiaí, SP. Revista Brasileira de Botânica, São Paulo, n. 12, p. 85 - 98, 1989.

NEWSTROM, L. E.; FRANKIE, G. W.; BAKER, H. G. A new classification for plant phenology based on flowering patterns in lowland tropical rain forest trees at La Selva, Costa Rica. Biotrópica, St. Louis, v. 26, n. 2 p. 141 - 159, 1994.

OLIVEIRA, D. M. T. Morfologia comparada de plântulas e plantas jovens de leguminosas arbóreas nativas: espécies de Phaseoleae, Sophoreae, Swartzieae e Tephrosieae. Revista Brasileira de Botânica, São Paulo, v. 24, n. 1, p. 85 - 97, 2001.

PÁSZTOR, Y. P. C. Métodos usados na colheita de sementes. Silvicultura em São Paulo. Boletim Técnico do Serviço Florestal, São Paulo, v. 1, n. 2, p. 305 - 323, 1963.

PIÑA-RODRIGUES, F. C. M.; FREIRE, J. M.; SILVA, L. D. Parâmetros genéticos para colheita de sementes de espécies florestais. In: PIÑA-RODRIGUES, F. C. M; FREIRE, J. M.; LELES, P. S. S.; BREIER, T. B. (Eds.). Parâmetros técnicos para produção de sementes florestais. 1. ed. Seropédica: Rioesba - Rede Mata Atlântica de Sementes Florestais, 2007. p. 51 - 102.

POLHILL, R. M. Papilionoideae. In: POLHILL, R. M.; RAVEN, P. H. (Eds.). Advances in Legume Systematics part I. Royal Botanic Gardens, Kew, 1981. 425 p.

REIS, A.; KAGEYAMA, Y. P. Restauração de áreas degradadas utilizando interações interespecíficas. In: KAGEYAMA, P. Y.; OLIVEIRA, R. G.; MORAES, L. F. D.; ENGEL, V. L.; GANDARA, F. B. (Orgs.). Restauração Ecológica de Ecossistemas Naturais. Botucatu-SP: FEPAF, 2008. p. 91 - 110.

RIO GRANDE DO SUL. Governo do Estado. Secretaria Estadual do Meio Ambiente. Relatório Final do Inventário Florestal Contínuo do Rio Grande do Sul. Porto Alegre: SEMA/UFSM, 2001. 706 p. v. 1, 2. 
SILVA, L. D; HIGA, A. R. Planejamento e implantação de pomares de sementes de espécies florestais nativas. In: HIGA, A. R; SILVA, L. D. (Eds.). Pomar de sementes de espécies florestais nativas. Curitiba: FUPEF, 2006. 266 p.

SOUZA, L. A. de. Morfologia e anatomia vegetal: célula, tecidos, órgãos e plântula. Ponta Grossa: UEPG, 2003. 259 p.

SOUZA, V. C.; LORENZI, H. Botânica sistemática: guia ilustrado para identificação das famílias de fanerógamas nativas e exóticas no Brasil, baseado em APG II. 2. ed. Nova Odessa, SP: Instituto Plantarum, 2008. 768 p.

VIDAL, W. N.; VIDAL M. R. R. Botânica - organografia. Quadros sinóticos ilustrados de fanerógamos. 4. ed. Viçosa: UFV, 2000. 124 p. 